\title{
Epinephrine in digital blocks: refuting dogma
}

\author{
Peter G. Katis, MD
}

\begin{abstract}
In the medical community there is a widely held belief that epinephrine should not be used with lidocaine when attempting a digital block because it will cause tissue gangrene. This belief is reinforced by several of the more prominent emergency textbooks, but a review of the medical literature fails to reveal a sound basis for this dogma.

Key words: lidocaine, epinephrine, finger

RÉSUMÉ

Au sein de la communauté médicale, il existe une notion très répandue selon laquelle on ne doit pas utiliser de l'épinéphrine avec de la lidocaïne lors d'une tentative de bloc digital en raison du risque de gangrène. Cette notion est renforcée par plusieurs manuels de médecine parmi les plus reconnus. Or, une revue de la littérature médicale ne fournit aucune base solide à ce dogme.
\end{abstract}

\section{Introduction}

The conventional teaching is ingrained: When performing a digital ring block, lidocaine preparations containing epinephrine should never be used, for fear they will cause an ischemic finger or toe. This belief has become medical dogma, and it is taught to generation after generation of medical students. The rationale is simple: Epinephrine activates alpha receptors in vascular endothelium, causing constriction of peripheral blood vessels. ${ }^{1}$ In end arteries, vasoconstriction will lead to ischemic necrosis of the involved tissue. The logic is compelling, but is the conclusion valid?

\section{The textbooks}

Tintinalli's most recent Emergency Medicine: a Comprehensive Study Guide states: "Epinephrine should never be used in an end-arterial field, e.g., digits, pinna, nose, penis."' Rosen's current Emergency Medicine: Concepts and
Clinical Practice is less dogmatic but offers the following: "Vasoconstrictors should be avoided in most wounds but can be used to prolong the effect of regional blocks (except in fingers or toes) and to decrease bleeding." ${ }^{3}$ Thus, these highly regarded emergency medicine textbooks agree with the classical teaching.

\section{The literature}

A PubMed search of the National Library of Medicine's MEDLINE database, using the terms "lidocaine" and "epinephrine" and "finger" with no specified limits generated 15 journal citations. Eleven papers were excluded from this discussion: 3 were written in a language other than English, 2 dealt with accidental epinephrine injection from an autoinjector device, 2 pertained to brachial plexus nerve blocks, 1 addressed digital perfusion in patients who received intra-oral injections, 1 discussed topical anesthesia (LET vs. EMLA), 1 described the role of endogenous epinephrine in vasoconstriction and 1 discussed phentolamine

Assistant Director, Emergency Medicine, University Health Network, Toronto, Ont.; Lecturer, Department of Family and Community Medicine, University of Toronto, Toronto

Received: Feb. 3, 2003; final submission: Mar. 24, 2003; accepted: Apr. 4, 2003

This article has been peer reviewed.

Can J Emerg Med 2003;5(4):245-6 
reversal of epinephrine-induced vasospasm. The remaining 4 papers are relevant to this discussion.

In a 1998 paper, Wilhelmi and colleagues described using a 1\% lidocaine solution and 1:100 000 or 1:200 000 epinephrine (total volume, 4 to $6 \mathrm{~mL}$ ) to treat 23 patients with finger injuries. ${ }^{4}$ The authors performed fracture reductions, laceration and tendon repairs, lesion excisions and nail bed repairs with no apparent complications.

In 2001, the same authors published a randomized double-blind trial comparing 1\% lidocaine with 1:200 000 epinephrine $(n=31)$ vs. $1 \%$ lidocaine alone $(n=29)$ for posttraumatic or elective digital procedures. ${ }^{5}$ In this study, the anesthetic solutions were infiltrated directly into the involved fingers using a 30-gauge needle. The authors documented no complications in the epinephrine-containing group, and reported that 1 of 31 patients (3.2\%) in the epinephrine group versus 5 of $29(17.2 \%)$ in the lidocaine only group required an additional injection to maintain anesthesia. Tourniquets were required for hemostasis in 9 (29\%) of 31 patients in the epinephrine group versus 20 (69\%) of 29 patients in the lidocaine only group $(p<0.002)$. These authors now routinely use epinephrine for digital blocks in their institution and report that there have been no episodes of digital gangrene in 121 patients treated.

In 1998, Sylaidis and coworkers used $2 \%$ lidocaine with a higher (1:80 000) concentration of epinephrine to perform digital blocks in 100 consecutive patients. ${ }^{6}$ In this prospective study of digital arterial perfusion, the authors noted a temporary reduction in digital blood flow yet finger perfusion was maintained in every case.

The most compelling paper was published by Denkler, who searched Index Medicus for the years 1880 to 1966, examined major textbooks from 1900 to 2000 and reviewed the National Library of Medicine's electronic medical database from 1966 to 2000 . This 120 -year review of the world's literature uncovered 21 cases of digital gangrene in the context of epinephrine use; however, the author notes that in all these cases, multiple other conditions, including hot soaks, tight tourniquets and infection, were also present. None of the 21 cases involved lidocaine (all were related to older anesthetics like cocaine and eukain) and in 17 cases, epinephrine concentrations were unknown because the dilution was formulated manually rather than by standard commercial methods. Denkler found no reports of digital gangrene after the introduction of standardized commercial lidocaine with epinephrine in 1948, and concluded that there is no consistent evidence that current preparations of local anesthesia with epinephrine cause digital necrosis. ${ }^{6}$

The evidence suggests an absence of harm when using epinephrine in digital nerve blocks; however, there are lim- itations to the studies quoted. Some were drawn from the plastic surgery literature, their sample sizes tend to be small, and a significant proportion of patients studied did not have traumatic injuries. Consequently, their results may not be directly applicable to the emergency department, where most patients have traumatic injuries and where rare, low-likelihood complications may become apparent based on the large volume of patients treated.

What is clear is that digits have, on occasion, demonstrated a remarkable resistance to ischemic insults. Severed fingers have been successfully reimplanted after up to 42 hours of warm ischemia, ${ }^{8}$ although this type of example should by no means be taken to represent typical digital viability or a desirable event. What is also clear is that it is time to re-examine and challenge the medical dogma forbidding epinephrine use in digital blocks and proceed with clinical trials in the emergency setting.

\section{Conclusion}

The widely held belief that epinephrine cannot be used with lidocaine to perform digital blocks is not supported by the medical literature. Epinephrine may, in fact, reduce the need for tourniquets and repeated digital injections, and there are no modern-day reports to suggest that epinephrine in commercial lidocaine preparations causes finger gangrene.

\section{Competing interests: None declared.}

\section{References}

1. Ganong WF. Review of medical physiology. 17th ed. Norwalk: Appleton \& Lange; 1995. p. 330.

2. Liebelt E, Levick N. Acute pain management, analgesia, and anxiolysis in the adult patient. In: Tintinalli J, Kelen G, Stapczynski J, editors. Emergency medicine: a comprehensive study guide. 5th ed. New York: McGraw-Hill; 2000. p. 251-68.

3. Simon B, Hern HG. Wound management principles. In: Marx J, editor. Rosen's emergency medicine: concepts and clinical practice. 5th ed. St. Louis: Mosby; 2002. p. 737-51.

4. Wilhelmi BJ, Blackwell SJ, Miller J, Mancoll JS, Phillips LG. Epinephrine in digital blocks: revisited. Ann Plast Surg 1998;41(4):410-4.

5. Wilhelmi BJ, Blackwell SJ, Miller JH, Mancoll JS, Dardano T, Tran A, et al. Do not use epinephrine in digital blocks: myth or truth? Plast Reconstr Surg 2001;107(2):393-7.

6. Sylaidis P, Logan A. Digital blocks with adrenaline: an old dogma refuted. J Hand Surg [Br] 1998;23(1):17-9.

7. Denkler K. A comprehensive review of epinephrine in the finger: to do or not to do. Plast Reconstr Surg 2001;108(1):114-24.

8. Baek SM, Kim SS. Successful digital replantation after 42 hours of warm ischemia. J Reconstr Microsurg 1992;8(6):455-8.

Correspondence to: Dr. Peter Katis, Toronto General Hospital, R. Fraser Elliot Building, GS-434, 200 Elizabeth St., Toronto ON M5G 2C4; 416 340-3856, fax 416 340-4300, peter.katis@uhn.on.ca 